\title{
A Study of Clinical Profile of Primary Extranodal Lymphomas in a Tertiary Care Institute in South India
}

\begin{abstract}
Context: Primary extranodal lymphoma ( $\mathrm{pENL}$ ) refers to group of disorders arising from tissues other than lymph nodes. The incidence of pENL is increasing and is probably due to better diagnostic immunophenotyping and imaging modalities. Hence, this study was undertaken to ascertain the incidence, distribution, and histological subtypes of extranodal non-Hodgkin lymphoma (NHL) in a tertiary care institute in South India. Subjects and Methods: This was a retrospective study of patients diagnosed to have histologically proven NHL. The demographic and clinical features, laboratory parameters, imaging findings, histopathology, and immunophenotyping were documented. The lymphomas were grouped as extranodal and nodal. The data were tabulated in a Microsoft Excel sheet, and descriptive analysis was done. Results: Primary extranodal NHLs constituted $35.96 \%(41 / 114)$ of all NHLs. The B symptoms were less common in pENL compared to nodal NHL. Gastrointestinal tract (GIT) constituted the most common extranodal site (19/41, 46.34\%), and diffuse large B-cell lymphoma (DLBCL) was the most common histological subtype. Majority $(40 / 41,97 \%)$ of the patients with pENL were immunocompetent. 31/41 (75\%) patients were in Stage I-II compared to 58/73 (79.4\%) patients in Stage III-IV in nodal NHL. Conclusions: Primary extranodal NHL constituted about one-third of patients diagnosed to have NHL at our center with the GIT being the most common site of presentation and DLBCL being the most common histology. A strong suspicion of NHL at an extranodal site with appropriate pathological and immunophenotyping evidence is needed to establish the diagnosis of a pENL.
\end{abstract}

Keywords: Diffuse large B cell, extranodal, lymphoma, Non-Hodgkin

\section{Introduction}

Non-Hodgkin lymphoma (NHL) is a group of malignant lymphoproliferative disorders arising predominantly in the lymph nodes with heterogeneous clinical and histological characteristics. At least $25 \%$ of NHL originates from tissues other than lymph nodes and sometimes even from sites that do not contain lymphoid tissue. ${ }^{[1]}$ These are referred to as primary extranodal lymphomas (pENLs). pENL is a frequent diagnostic challenge to the clinicians and pathologists due to their varied clinical presentations, morphological mimicry, and molecular alterations.

Over the last two decades, the incidence of the lymphomas arising in the extranodal sites has shown a rapid increase, especially in the central nervous system, the gastrointestinal tract (GIT) and the skin. This may be attributed to environmental factors, chronic infections, immunosuppressive disorders such as AIDS, autoimmune disorders, and

This is an open access article distributed under the terms of the Creative Commons Attribution-NonCommercial-ShareAlike 3.0 License, which allows others to remix, tweak, and build upon the work non-commercially, as long as the author is credited and the new creations are licensed under the identical terms.

For reprints contact: reprints@medknow.com immunosuppressive treatments. ${ }^{[2,3]}$ Although there are many case reports and series dealing with extranodal lymphoma of the various sites of the body, the literature on pENL as a group is limited. Hence, this study was undertaken to ascertain the incidence, anatomical distribution, histological subtypes, and clinical manifestations of pENL from a tertiary care institute in South India.

\section{Subjects and Methods}

This was a retrospective study of the records of patients admitted to the Department of Medical Oncology and diagnosed to have NHL based on histopathological biopsy evidence from January 2012 to December 2015. During this period, 150 NHL were diagnosed, and 114 patient records were studied. The 36 patient records were excluded due to incomplete evaluation and lack of data in the records.

All patients underwent biopsy, and the tissue was processed and stained

\footnotetext{
How to cite this article: Pai $A$, Kannan $T$, Balambika RG, Vasini V. A study of clinical profile of primary extranodal lymphomas in a tertiary care institute in South India. Indian J Med Paediatr Oncol 2017;38:251-5.
}

\section{Ananth Pai, Thiruvengadasamy Kannan, RG Balambika, Vindhya Vasini}

Department of Medical Oncology, Sri Venkateswara Institute of Medical Sciences, Tirupati, Andhra Pradesh, India

Address for correspondence: Dr. Ananth Pai, Department of Medical Oncology, Sri Venkateswara Institute of Medical Sciences, Tirupati - 517 507, Andhra Pradesh, India. E-mail:dr.pai.ananth@gmail. com

Access this article online Website: www.ijmpo.org DOI: 10.4103/ijmpo.ijmpo_82_16 Quick Response Code:

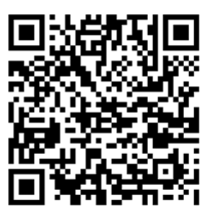


with hematoxylin and eosin. The patients with nodal lymphoma underwent excisional biopsy, and the patients with extranodal lymphoma were diagnosed based on the operated histopathological specimen or a guided biopsy from the site. Immunohistochemistry (IHC) studies were performed using a panel of antibodies depending on the morphology of the biopsy. Molecular diagnostic techniques were not performed in any of the cases due to lack of facilities.

The data pertaining to patients' demography, clinical symptoms and signs, immune status, routine complete blood count, imaging findings, operative notes if any and treatment received were obtained from the medical records. The positron emission test with computerized tomogram (PET-CT) reports was also documented if they were incorporated in the staging evaluation. The clinical stage was classified according to the Ann Arbor classification. The involvement of the lymph nodes and Waldeyer's ring was defined as nodal lymphoma, and the involvement of other organs was defined as extranodal lymphoma. ${ }^{[4]}$

The patients were considered to be completely staged when there was adequate information available related to the history, status of peripheral lymph nodes (clinically palpable), Waldeyer's ring (documented by an ENT surgeon), mediastinal lymph nodes (based on chest CT scan), abdominal lymph nodes, sizes of liver and spleen (based on abdominal CT scan) as well as the reports of the peripheral blood and bone marrow aspiration and trephine biopsy.

The treatment constituted predominantly chemotherapy as per the standard practicing guidelines. The clinicopathological features of the pENL were analyzed and compared with primary nodal NHL studied during the study (2012-2015).

\section{Results}

Primary extranodal NHL constituted 35.96\% (41/114) of all NHL studied during this period. The mean age at presentation for the pENL and primary nodal NHL was 48.2 years and 54.2 years, respectively (range $5-81$ years). There were 20 male and 21 female in the pENL group compared to 44 males and 29 females in the nodal lymphoma group [Table 1]. The peak incidence was in the sixth decade in the pENL group and fifth decade in the nodal NHL group [Figure 1].

Abdominal pain associated with vomiting (18/41, 44\%) was the most common presenting symptom in patients with pENL. The mean duration of symptoms in pENL was 3.6 months compared to 4 months in nodal NHL. The B symptoms were less common in patients with pENL compared to those with nodal NHL. Only one patient with pENL was seropositive for HIV whereas HBV was positive in three patients with pENL and one patient with nodal NHL. No patient was positive for HCV infection.

\begin{tabular}{lcc}
\hline \multicolumn{3}{c}{ Table 1: Comparison of features and laboratory values } \\
\hline & pENL & Nodal NHL \\
\hline Mean age (years) & 48.2 & 54.2 \\
Median age (years) & 51 & 54 \\
Peak incidence (decade) & Sixth & Fifth \\
Male:female ratio & $1: 1.05$ & $1.5: 1$ \\
Mean duration of symptoms (months) & 3.6 & 4 \\
Fever (\%) & $9 / 41(22)$ & $20 / 73(30)$ \\
Loss of weight (\%) & $11 / 41(26.8)$ & $23 / 73(31.5)$ \\
Mean hemoglobin (g/dL) & 10.98 & 11.52 \\
Mean ESR (mm at $\left.1^{\text {st }} \mathrm{h}\right)$ & 54.26 & 57.38 \\
Mean LDH (IU/L) & 679.68 & 679.69 \\
\hline
\end{tabular}

ESR - Erythrocyte sedimentation rate; LDH - Lactate dehydrogenase; pENL - Primary extranodal lymphoma; NHL - Non-Hodgkin lymphoma

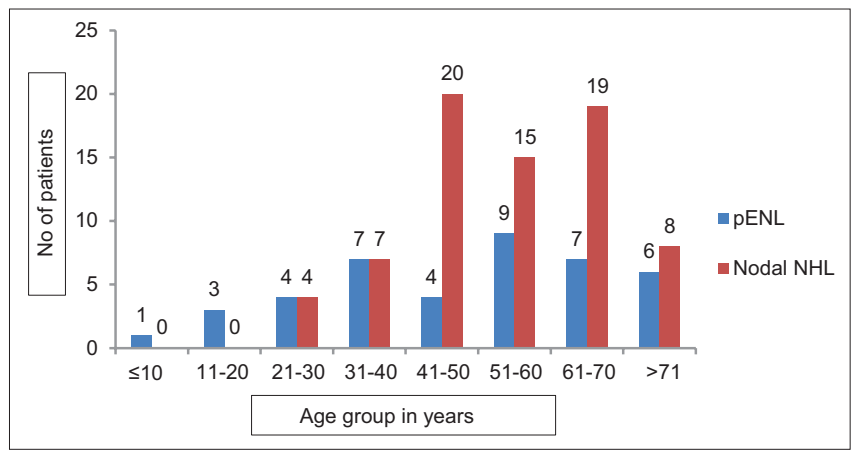

Figure 1: Age group distribution

Among the patients in pENL group, 21 patients underwent a major surgical procedure as a part of emergency management and for the diagnosis (GIT, central nervous system [CNS], and uterus/ovary) while 20 patients were diagnosed based on image-guided biopsy only. Among the nodal NHL, almost all the patients were diagnosed based on an excisional biopsy of the lymph node.

PET-CT was done in 67 patients as a part of staging evaluation. 27 patients had bone marrow involvement by PET-CT, and 38 patients were negative for bone marrow involvement.

The GIT was the most common site of pENL (19/41, 46.34\%) (stomach 10, small bowel 5, and colon 4) followed by nasopharynx/oropharynx (4/41, 9.75\%), testis $(3 / 41,7.3 \%)$, uterus/ovary $(3 / 41,7.3 \%)$, thyroid $(2 / 41,4.8 \%)$, and central nervous system $(2 / 41,4.8 \%)$. Long bones (tibia), maxillary sinus, skin, and paraspinal soft tissues (one patient each) were the other rare anatomic sites of pENL [Figure 2].

Extranodal involvement was seen among 30 patients $(41 \%)$ in the nodal NHL group with the parotid $(9 / 73,12.32 \%)$ being the most common site of involvement followed by Waldeyer's ring and breast ( 3 patients each, $4.1 \%$ each) and pancreas and kidneys (two patients each, $2.7 \%$ each) and testis (one patient). 
Diffuse large B-cell lymphoma (DLBCL, not otherwise specified), B-cell NHL unclassified and $\mathrm{T}$ cell were the three most common histological types observed. Follicular lymphoma, small lymphocytic lymphoma, and anaplastic large cell lymphoma, seen among nodal NHL, were not seen at extranodal sites as shown in Table 2.

IHC for CD20 was positive in 31 patients $(75.6 \%)$ in the pENL group and 58 patients $(79.4 \%)$ in the nodal NHL group.

Most of the patients in the pENL group were diagnosed to have Stage I/II lymphoma whereas Stage III/IV was more common in patients with nodal NHL. 31/41 (75\%) patients in $\mathrm{pENL}$ were diagnosed to have Stage I-II compared to $58 / 73(79.4 \%)$ patients in nodal NHL having Stage III-IV.

Most of the patients were treated with chemotherapy following the diagnosis. The most common chemotherapy used was cyclophosphamide, doxorubicin, vincristine, and prednisolone regimen, and rituximab was a part of chemotherapy in total 33 patients. 12/31 (38.7\%) CD20-positive patients in pENL and 21/58 (36.2\%) CD20-positive patients in nodal NHL received rituximab. The average number of cycles administered in pENL group

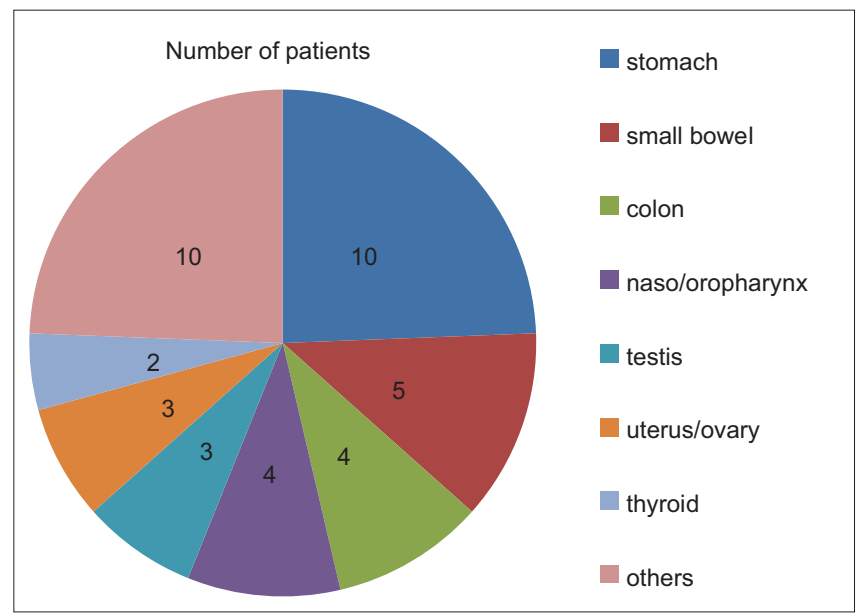

Figure 2: Site wise distribution

\begin{tabular}{lcc}
\hline \multicolumn{3}{c}{ Table 2: Histology of the lymphomas } \\
\hline Histology & pENL & Nodal NHL \\
\hline DLBCL & 19 & 24 \\
BL, unclassified & 14 & 25 \\
T-cell lymphoma & 6 & 9 \\
FL & 0 & 9 \\
SLL & 0 & 3 \\
Mantle cell lymphoma & 0 & 2 \\
MALToma & 2 & 0 \\
ALCL & 0 & 1 \\
\hline
\end{tabular}

pENL - Primary extranodal lymphoma; NHL - Non-Hodgkin lymphoma; DLBCL - Diffuse large B-cell lymphoma; FL - Follicular lymphoma; SLL - Small lymphocytic lymphoma; ALCL - Anaplastic large cell lymphoma; BL - B-cell lymphoma; MALToma - Mucosa-associated lymphoid tissue lymphoma was 4.2 cycles compared to 5.4 cycles in the nodal NHL group.

The overall follow-up was poor in both groups. Only $14 / 41(34.1 \%)$ patients followed up, and the median progression-free survival (PFS) was 17 months (range 2-46 months) in the pENL group. Similarly, only $37 / 73(50.6 \%)$ patients diagnosed with the nodal NHL followed up, and the median PFS was 13 months (range 2-45 months).

\section{Discussion}

Primary extranodal lymphoma (pENL) is a heterogeneous disease with respect to the geographical distribution, ethnic variation, anatomical localization, etiological, and morphological diversities. ${ }^{[5]}$ The frequency of the primary extranodal NHL is high where the total lymphoma incidence is high. A study by Singh et al. ${ }^{[6]}$ from North India reported an incidence of 44\% (106/241 cases over 3 year period). Similarly, a study from South India by Padhi et al. ${ }^{[7]}$ have a reported an incidence of $22 \%$. Studies from Pakistan, ${ }^{[8]}$ Korea, $^{[9]}$ and China ${ }^{[10]}$ have also reported incidences ranging from $45 \%$ to $62 \%$. Our study showed the incidence to be $35.96 \%$ which is higher than the other studies from South India.

In this present study, in comparison to the patients with nodal NHL, patients diagnosed to have pENL were younger (mean 48.2 years vs. 54.2 years) with lesser duration of symptoms and lesser B symptoms which are comparable with a study by Padhi et al. from South India. The gender distribution was equal in the pENL group with slight female preponderance which was different from the studies published earlier (1:1.05 vs. 2:1). ${ }^{[7]}$ DLBCL (not otherwise specified), B-cell NHL unclassified, and $\mathrm{T}$ cell were the three most common histological types observed in our study, and this is comparable to the study by Singh et al. ${ }^{[6]}$ and Padhi et al. ${ }^{[7]}$ Follicular lymphoma, small lymphocytic lymphoma, and anaplastic large cell lymphoma, seen among nodal NHL, were not seen at extranodal sites and this may be possibly be due to the geographic variation in molecular expression profiling of the lymphomas as reported by Biagi and Seymour et al. ${ }^{[11]}$

A comparative review of literature of the pENL with regard to the clinicopathological presentation is presented in Table 3.

The incidence of the GIT lymphomas has been increasing throughout the world, and it has now been reported to be the most common site of involvement among the extranodal lymphomas. ${ }^{[12]}$ The head and neck region including the Waldeyer's ring have reported to be common sites of origin of pENL in few studies from India, ${ }^{[6]}$ Pakistan, ${ }^{[8]}$ and China. ${ }^{[10]}$ The common sites of origin of $\mathrm{pENL}$ in our study were GIT followed by head and neck region, and this is comparable to the other studies from Asian continent. The pattern of involvement of the primary gastrointestinal 


\begin{tabular}{|c|c|c|c|c|c|c|c|}
\hline \multirow[t]{2}{*}{ Author and year } & \multirow{2}{*}{$\begin{array}{c}\text { Total number } \\
\text { of NHL }\end{array}$} & \multirow[t]{2}{*}{ Period } & \multirow{2}{*}{$\begin{array}{l}\text { Number of } \\
\text { pENL }(\%)\end{array}$} & \multirow{2}{*}{$\begin{array}{l}\text { Common anatomical } \\
\text { site }\end{array}$} & \multicolumn{2}{|c|}{ Histopathology } & \multirow[t]{2}{*}{ Remark } \\
\hline & & & & & Nodal & Extranodal & \\
\hline $\begin{array}{l}\text { Singh et al., 2003, } \\
\text { India }\end{array}$ & 241 & 3 & $106(44)$ & $\begin{array}{l}\text { Head and neck (tonsil), } \\
\text { GIT (stomach) }\end{array}$ & DLBCL & DLBCL & $\begin{array}{l}\text { Poor oro-dental } \\
\text { hygiene, tobacco } \\
\text { chewing }\end{array}$ \\
\hline $\begin{array}{l}\text { Yoon et al., 2010, } \\
\text { Korea }\end{array}$ & 48 & 11 & $48(100)$ & $\begin{array}{l}\text { Adrenal, esophagus, } \\
\text { prostate, pancreas }\end{array}$ & - & DLBCL & Bad prognosis \\
\hline $\begin{array}{l}\text { Nagi et al., 2010, } \\
\text { Pakistan }\end{array}$ & - & 5 & 147 & GIT, NNPS & DLBCL, FL & DLBCL, ALCL, BL & Male:female $=1: 1$ \\
\hline $\begin{array}{l}\text { Yang et al., 2011, } \\
\text { China }\end{array}$ & 5549 & 9 & 2968 (53.5) & $\begin{array}{l}\text { Waldeyer's ring, } \\
\text { NNPS, GIT }\end{array}$ & $\begin{array}{l}\text { DLBCL, FL, } \\
\text { SLL }\end{array}$ & $\begin{array}{l}\text { DLBCL, ENKTCL, } \\
\text { MALT }\end{array}$ & $\begin{array}{l}\text { High frequency of } \\
\text { ENKTCL, EBV } \\
\text { positivity }\end{array}$ \\
\hline $\begin{array}{l}\text { Somanath Padhi } \\
\text { et al., 2012, India }\end{array}$ & 308 & 5 & $68(22)$ & Brain, GIT & $\begin{array}{l}\text { DLBCL, FL, } \\
\text { ALCL }\end{array}$ & $\begin{array}{l}\text { DLBCL, MALT, } \\
\text { B-cell NHL (U) }\end{array}$ & $\begin{array}{l}\text { Early stage, } \\
\text { immunocompetent }\end{array}$ \\
\hline $\begin{array}{l}\text { Present study, } \\
\text { 2015, South India }\end{array}$ & 114 & 4 & $41(35.96)$ & GIT, NNPS, testis & $\begin{array}{l}\text { DLBCL, B-cell } \\
\text { NHL (U), FL, } \\
\text { SLL }\end{array}$ & $\begin{array}{l}\text { DLBCL, B-cell } \\
\text { NHL (U) }\end{array}$ & $\begin{array}{l}\text { Early stage, } \\
\text { immunocompetent, } \\
\text { less B symptoms, } \\
\text { Male:female }=1: 1.05\end{array}$ \\
\hline
\end{tabular}

lymphoma in our study was similar to that reported in the Western population and in India with the stomach being the most common site of involvement, followed by small intestine and large intestine. ${ }^{[2,12]}$ The incidence of primary CNS lymphoma cases was low in our study as most of the cases were immunocompetent.

The pENL have been known to have complex biological behavior as shown in various studies [Table 3]. Inspite of significant diagnostic and treatment developments, the therapeutic outcome has been worse for patients with pENL involving rare sites as shown by Yun et al. ${ }^{[13]}$ Studies have also shown that the age, stage of the lymphoma, performance status, and serum LDH level have been independent prognostic variables, whereas the site of involvement (nodal versus extranodal site) did not bear any prognostic significance as shown by Lal et al. ${ }^{[14]}$ In this present study, at initial presentation patients with pENL were younger, had lesser B symptoms, and lesser bone marrow involvement.

\section{Conclusions}

This study showed that the incidence of pENL in South India is comparable to the data from other parts of India and Asia. The GIT was the most common site of involvement among the pENL as seen in other studies. Compared to previously published studies of extranodal lymphoma series, no major specific differences were noted with respect to the gender preponderance and the histopathology. Majority of the patients presented at younger age, with early stage of lymphoma and were immunocompetent. This study being mostly an epidemiological and morphological study, failed to address the outcomes as the long-term follow-up data pertaining to the survival analysis are lacking. However, we do believe at this point of time that more studies of similar kind with focus on outcomes and also highlighting the genetic profile, must be carried out to understand the complex biology of the primary extranodal pENLs.

\section{Acknowledgment}

We thank and acknowledge the inputs from the Departments of Pathology, Radiology, and Nuclear Medicine.

Financial support and sponsorship

Nil.

\section{Conflicts of interest}

There are no conflicts of interest.

\section{References}

1. Evans LS, Hancock BW. Non-Hodgkin lymphoma. Lancet 2003;362:139-46.

2. Zucca E, Roggero E, Bertoni F, Cavalli F. Primary extranodal non-Hodgkin's lymphomas. Part 1: Gastrointestinal, cutaneous and genitourinary lymphomas. Ann Oncol 1997;8:727-37.

3. Zucca E, Roggero E, Bertoni F, Conconi A, Cavalli F. Primary extranodal non-Hodgkin's lymphomas. Part 2: Head and neck, central nervous system and other less common sites. Ann Oncol 1999; 10:1023-33.

4. Carbone PP, Kaplan HS, Musshoff K, Smithers DW, Tubiana M. Report of the committee on Hodgkin's disease staging classification. Cancer Res 1971;31:1860-1.

5. Anderson JR, Armitage JO, Weisenburger DD. Epidemiology of the non-Hodgkin's lymphomas: Distributions of the major subtypes differ by geographic locations. Non-Hodgkin's Lymphoma Classification Project. Ann Oncol 1998;9:717-20.

6. Singh D, Kumar L, Goyal H, Raina V, Bijlani L, Wadhwa J. 
Primary extranodal non-Hodgkin's lymphoma in northern India. Proc Am Soc Clin Oncol 2003;22:2457.

7. Padhi S, Paul TR, Challa S, Prayaga AK, Rajappa S, Raghunadharao $\mathrm{D}$, et al. Primary extra nodal non Hodgkin lymphoma: A 5 year retrospective analysis. Asian Pac J Cancer Prev 2012;13:4889-95.

8. Nagi AH, Al Minawy L, Naseem N, Henna SN, Naveed IA. A study of the morphological patterns of extranodal non-Hodgkin lymphoma in Pakistani and Saudi populations. Biomedica 2010;26:118-23.

9. Yoon SO, Suh C, Lee DH, Chi HS, Park CJ, Jang SS, et al. Distribution of lymphoid neoplasms in the Republic of Korea: Analysis of 5318 cases according to the World Health Organization classification. Am J Hematol 2010;85:760-4.

10. Yang QP, Zhang WY, Yu JB, Zhao S, Xu H, Wang WY, et al. Subtype distribution of lymphomas in Southwest China: Analysis of 6,382 cases using WHO classification in a single institution.
Diagn Pathol 2011;6:77.

11. Biagi JJ, Seymour JF. Insights into the molecular pathogenesis of follicular lymphoma arising from analysis of geographic variation. Blood 2002;99:4265-75.

12. Arora N, Manipadam MT, Pulimood A, Ramakrishna BS, Chacko A, Kurian SS, et al. Gastrointestinal lymphomas: Pattern of distribution and histological subtypes: 10 years experience in a tertiary centre in South India. Indian J Pathol Microbiol 2011;54:712-9.

13. Yun J, Kim SJ, Kim JA, Kong JH, Lee SH, Kim K, et al. Clinical features and treatment outcomes of non-Hodgkin's lymphomas involving rare extranodal sites: A single-center experience. Acta Haematol 2010;123:48-54.

14. Lal A, Bhurgri Y, Vaziri I, Rizvi NB, Sadaf A, Sartajuddin S, et al. Extranodal non-Hodgkin's lymphomas - A retrospective review of clinico-pathologic features and outcomes in comparison with nodal non-Hodgkin's lymphomas. Asian Pac J Cancer Prev 2008;9:453-8. 